\title{
Development and implementation of extracurricilar environmental event for secondary school students
}

\author{
Elena Ivanova $^{1, *}$, Mikhail Evdokimov ${ }^{1}$, Elena Evdokimova ${ }^{1}$ \\ ${ }^{1}$ Moscow Region State University, 10A, Radio str, 105005, Moscow, Russia
}

\begin{abstract}
The results of the phased development and implementation of the educational environmental event "Elk Island - Clean Forest" are given as part of the environmental education of middle school students in garbage collection within the boundaries of a specially protected natural area, including legal, methodological and organizational stages, the implementation of which allowed for an extracurricular environmental event, identify problems of a methodological and organizational nature that require more detailed study, identify the effectiveness of individual components, and formulate some recommendations for similar events. The methodology of the ecological campaign "Clean Games", adapted for participants of secondary school age (12-16 years), as well as the development and results of an extracurricular environmental event "Elk Island - Clean Forest" are presented. The results obtained make it possible to assess the possibility of using the existing methodology and the need for its adjustment, taking into account the age characteristics of students, as well as the quality of learning material and the presence of increased interest of students in this problem.
\end{abstract}

\section{Introduction}

The environmental issue is an important component of both environmental education and the conditions for the maintenance and use of protected natural territories [1], and the introduction of an element of competition among children and adolescents significantly increases the result of the event $[2,3]$.

The object of the study was a section of the territory of the National Park "Elk Island" within the boundaries of the Korolev urban district of the Moscow Region. The subject of the study is an environmental event with the participation of schoolchildren.

The purpose of the study is the development and implementation of an environmental event within the boundaries of a specially protected natural area of federal significance National Park "Elk Island" as part of the environmental education of secondary school students [4].

To achieve this goal, the following tasks were solved: study of the methodology for the environmental campaign "Clean Games" to form an idea of the ongoing campaign;

\footnotetext{
* Corresponding author: ivelena2010@mail.ru
} 
personal participation of the active group in the environmental event "Clean Games" in order to study the applied (practical) significance of the campaign; development of the "Clean Games" methodology adapted for participants of secondary school age (12-16 years old); development and implementation of an extracurricular environmental event "Elk Island - Clean Forest".

The practical significance of the measure is to organize the debris removal of a specially protected natural area (SPNA), pollution of which, according to Russian law, is an administrative, and in some cases a criminal offense, through the interest and subsequent participation of schoolchildren in an environmental event $[1,4]$.

\section{Materials and methods}

The development and implementation of the environmental event included a number of stages carried out using various research methods:

In order to increase the interest and involvement of students at the stage of preparation and holding of the event, an active group was formed of interested students and those who expressed a desire, who had previously taken part in such events.

The result of passing the stage of collecting and analyzing diverse information on the problem under study is:

- analysis of regulatory and environmental documentation on the topic under study, the study of methods for organizing team collaboration, the study of the methods of conducting a team game to collect garbage (for example, the environmental campaign "Clean Games");

- personal participation of the active group in the environmental event "Clean Games" in order to study the applied (practical) value of the action, the conditions for evaluating the collected garbage by the buyer, and the use of the mobile application;

- the elaboration of the "Clean Games" methodology adapted for school age participants made it possible to adjust the existing methodology in terms of the location of the ecological route and escorting the group by an employee of the Environmental Center "NP "Elk Island", forming on-site teams by age and interests from participating singles, selecting additional opportunities for earning points that are most suitable for adolescents and children.

In the process of developing an environmental event, the following stages have been developed:

1. Legal (signing of an agreement on the use of the "Clean Games" methodology and coordination of the event with the administration of the Municipal Autonomous Educational Institution "Gymnasium No. 9", Korolev, and with the administration of the FSBI NP Elk Island).

2. Methodical (study of the methodology provided by the authors under the agreement; development of rules, safety measures, regulations; development of a methodology for organizing an educational game adapted for schoolchildren).

3. Organizational (acquaintance with the authors of the "Clean Games" methodology; participation of a group of activists in the All-Russian rally of the Clean Games coordinators - the Ecological Quest "Clean Guslitsa" and the event report; selection of a venue and determination of the date of the environmental event, development of a poster and press release for the Game, registering the Games on the "Clean Games" website; creating an event page on a social network; meeting with the head of the Elk Island Children's Ecological and Educational Center V.V. Solodushkin; developing an information sheet to attract participants, filling out the event's page, campaigning at the MAEI 
“Gymnasium No. 9", Korolev (environmental lesson on the separate collection of garbage), holding the Game and garbage collection.

The environmental event was carried out on the basis of a methodology adapted by teachers in accordance with the age characteristics of schoolchildren, including the rules of the event and the ecological route of the event [4], registration and formation of teams from participants, tasks (eco-quiz, competitions, individual tasks, etc.).

\section{Research results and discussion}

1. In accordance with the conditions for the implementation of the environmental measure to attract schoolchildren to the collection of garbage, the quest site is located within the buffer zone of the protected areas of federal significance "National Park "Elk Island".

The specially protected natural area under consideration belong to the category of "national parks", accordingly, "it is an environmental, environmental-educational and research institution, the territory of which includes natural complexes and objects of great environmental importance and are intended for use in environmental, educational, scientific and cultural goals and for regulated tourism" (Federal Law No. 33, Section III, Article 12, Clause 1), the main tasks of which are: preservation of existing and restoration of disturbed natural complexes, environmental education of the population, as well as the development and implementation of methods for the protection of natural objects (Federal Law No. 33, Section III, Article 13).

2. Elk Island National Park is partially located on the territory of the Korolev urban district of the Moscow Region.

Elk Island is a unique territory. Here, near the multimillion city, the nature of Central Russia in all its diversity has been preserved in its natural state: coniferous, birch and broad-leaved forests, sections of meadows and raised bogs, the outlets of Yauza with lakes and floodplains [3].

Species of plants and animals that are rare or subject to protection in Moscow and the Moscow region are quite widely represented in the park.

3. Games in the form of a team quest for garbage collection are held based on the existing methodology [5-7] developed by the team of founders of the "Clean Games" (hereinafter $\mathrm{CG})$.

In all cases, it is necessary: registration of the event through the official website of the "Clean Games" https://cleangames.ru; use of the symbols of "Clean Games"; use of the "Clean Games" mobile application; separate collection of garbage; lack of political symbols or appeals; garbage collection on the day of the event or the next day; presentation of prizes to winning teams; photographing the event.

The methodology provided by the authors of the project (transferring it without the permission of the authors is not allowed) contains detailed rules, a script for the Games, recommendations for attracting participants, sponsors, coordinating the event with local authorities, etc.). The organizer of the event can contribute ideas, contests, refine the methodology, taking into account the venue, the subject of his CG and the composition of the participants.

4. Due to the forthcoming entry into force of the new edition of federal law No. 89-FL "On Production and Consumption Wastes" dated December 25, 2018 in the city district of Korolev, educational institutions and teachers began to actively conduct environmental lessons on the separate collection of garbage [8]. In this regard, in September 2019, 10 lessons on this topic in parallels of 5-9 grades were held at the MAEI "Gymnasium No. 9". The purpose of the lessons was to attract schoolchildren to separate collection of garbage in 
the educational institution, at home, as well as a preliminary announcement about the possibility of training in separate collection during the school "Clean Games". In parallel, a group of activists campaigned in eight classes. The rules of the Games were briefly explained, information on the operation of the mobile application was provided, and contact details of the author as the coordinator of the Game were reported. Each interested person was given an information sheet containing: data on the place and time of the Game; driving directions; basic concepts; rules; graduation by points awarded to the team for separately collected garbage.

5. An adapted methodology for conducting an environmental event for schoolchildren to collect garbage within the borders of the NP "Elk Island".

The Games methodology provides for the general start time of the Game and the same collection time for all participants. The players clear the terrain indicated in the map of the Game. Given that the participants of the event are children and adolescents who would be dangerous to let go through the vast unlimited territory of the National Park, the teachers decided to change the scheme of action: from the start, participants accompanied by an employee of the Ecological Center "NP "Elk Island" (hereinafter referred to as the Center) and accompanying adults move along the ecological route, making stops and collecting garbage, without moving further from the trail away from the visibility zone. The route has a closed circuit, the starting and returning place is the Center. It was decided that in order to increase the level of environmental knowledge of adolescents, an eco-quiz will be held by an employee of the Center. During the game, participants can ask the employee questions about the geography, nature, ecology of the National Park.

It was decided to invite students of the MAEI "Gymnasium No. 9" to participate in the game in the form of friendly or family teams [9]. In accordance with the rules, the number of participants in a team should not exceed 4 people. It is necessary to choose the captain of the team, as well as the liaison person (the participant who will work with the mobile application). Due to the fact that not everyone could immediately determine the composition of the team, preliminary registration of the team through the "Clean Games" website (additional points) and at the venue were also supposed.

It is clear that in order to attract children and adolescents to participate, the competitive nature of the Game is not enough, additional interesting opportunities to earn points are needed [10]. In addition, it was necessary to consider that in order to maintain interest for children and adolescents, a change in the type of activity during the event was required. Based on the methodology of the Game worked out by teachers, it was decided to select the best opportunities for the school audience: check-ins (uploading photos of garbage accumulations to the mobile application before and after cleaning), artifacts (especially interesting finds), the contest "The Best Legend of the Artifact", photo hunting (successful footage of rare objects of nature), eco-quiz, competition for the best legend about an artifact.

Given the peculiarity of conducting children's and teenage events, when it is necessary to avoid periods of "standby time", which worsens the general mood of the team, teachers provided measures for the simultaneous conduct of certain stages of the game (for example, filling out eco-quiz forms by some participants while buying up garbage by others, etc.). Separate garbage collection was evaluated by the buyer. The purchase results were entered into the game's mobile application.

6. The results of the extracurricular environmental event "Elk Island - Clean Forest" are as follows:

The results of the game: 
- environmental component: 69 bags of garbage collected in the territory belonging to the Children's Ecological and Educational Center "National Park "Elk Island" were disposed;

- educational component: students gaining knowledge and skills on separate garbage collection, gaining knowledge about the native land, nature and ecology of protected areas of the NP "Elk Island";

- aesthetic component: the participation of students in the event in one of the most picturesque corners of the Moscow region;

- communicative component: "live" communication of participants, independent division into teams (friends, family), separation of powers within the team;

- motivating component: it is possible to continue similar activities, to conduct events in the future by participants in the implemented Game, as well as by their followers.

Problems identified in the course of the Game and requiring study in the organization of subsequent events:

- special attention should be paid to the safety of adolescents when organizing school "Clean Games", given their desire to take risks (go deep into the forest, collect dangerous and heavy garbage) in an effort to win the competition [7];

- the duration of the school "Clean Games" should be determined reasonably. It is necessary not only to carry out a change in the type of activity (physical, mental, rest), but also to avoid periods of forced waiting when organizing the Game.

The effectiveness of campaigning depends on the emphasis on the "particularly attractive" opportunities of the "Clean Games":

- the ability to use gadgets popular with teenagers to work with a mobile application;

- the presence of contests for additional points (the legend of the best artefact, environmental quiz) that allow adolescents to show their knowledge or imagination [9];

- positive emotions from working in a pre-completed team or meeting new people in a completed team at the venue.

Recommendations for school games based on the experience of the event "Elk Island Clean Forest":

- participation of employees of the National Park in the event allows increasing the level of schoolchildren knowledge about specially protected natural area;

- it is desirable to have the final placement of the collected bags in one warehouse so that adolescents can see a real tangible result from their volunteer activities;

- holding an event in a picturesque, preferably close and known place for the participants, improves the result of garbage collection not only from sports excitement, but also from the desire to improve this territory.

In the future, it is planned to hold similar games with students of educational institutions of the city district of Korolev of the Moscow region on the territory of the NP "Elk Island", subject to agreement (on the basis of the Agreement) with the organizers of the "Clean Games", as a result of which the participants will gain theoretical knowledge and practical skills in separate garbage collection, will receive local history and environmental knowledge about the natural component of the specially protected natural area of the NP "Elk Island".

\section{Conclusions}

In the process of project implementation, the following conclusions are formulated:

1. The "Clean Games" methodology, in many of its parameters, is optimally suited for holding a school event: team format, competition, use of a mobile application, the 
possibility of earning additional points by the assessment system for separate garbage collection and participation in competitions.

2. The adjustment of the "Clean Games" methodology adapted in accordance with the age characteristics of the participants touched on a number of key points: the location (isolation) of the ecological route, escorting the group by an employee of the Environmental Center, additional on-site registration of teams formed from single participants based on interests and age, selection from the methodology of the most interesting additional opportunities for earning points for schoolchildren (using a mobile application, photo hunting, competition "The Best Legend of Artifact", eco-quiz), the frequency of changing the type of activity, the organization of the stages of the game with the maximum avoidance of the period in the "standby mode".

3. Testing the adapted methodology for conducting an environmental event as part of the environmental education of schoolchildren confirmed the feasibility of adjusting the existing "Clean Games" methodology.

4. The implementation of an extracurricular environmental event showed: students master the environmental, educational, volunteer and a number of other components that are important for the educational event; the presence of organizational issues in need of improvement; conditions for effective campaigning; recommendations for similar events, taking into account the age characteristics of the participants.

5. As a result of the volunteer and educational game "Elk Island - Clean Forest", the area of the specially protected natural area of the NP "Elk Island" was cleaned, 69 bags of garbage were collected and disposed, 17 of them with mixed waste, 20 with plastic, 10 with metal, and 22 with glass.

\section{References}

1. O.Yu. Baranova, E.Yu. Ivanova, Sat: Geography and ecology: problems of science, practice and education. Materials of the international scientific-practical conference (2016)

2. G.P. Bobrenkova, System development of volunteering in Russia: from theory to practice: textbook.-method. Allowance (M., Sotis, 2013)

3. Elk Island Island National Park: problems and prospects, https://dervishv.livejournal.com/470643.html

4. O.Yu. Baranova, E.Yu. Ivanova, Collection of materials of the international scientific and methodological conference (Moscow, Ministry of Education of Moscow region. GOU VPO Moscow State Regional University, 2011)

5. The page of the Ecocvest "Clean Guslitsa", Guslitsa creative estate (formerly Mitrokhinskaya factory) https://vk.com/clean_guslitsa

6. A. Mottaeva, A. Ivashchenko, A. Ryattel, E3S Web of Conferences 164, 10038 (2020) https://doi.org/10.1051/e3sconf /202016410038

7. "Clean Games", https://cleangames.ru/about

8. M.Yu. Evdokimov, Sat.: Dobrodeev readings - 2018. II International scientific and practical conference (2018)

9. T.I. Krylova, O.V. Barentseva, Collection of scientific papers of the 2nd international scientific-practical conference "Good reading" of the Geographical and Environmental Faculty (Moscow, Moscow State Pedagogical University, 2018) 
10. M.Yu. Evdokimov, E.V. Evdokimova, Sat. Geography and region. Materials of the international scientific-practical conference (2015) 